\title{
Understanding Risk and Resilience to Natural Hazards
}

Tatural hazards threaten the
safety and economic wellbe-
ing of communities. These hazards
include sudden-onset hazards,
such as earthquakes, and slowly
emerging, chronic hazards, such
as those associated with climate
change. To help public officials,
emergency and other managers,
the business community, and at-
risk individuals reduce the risks
posed by such hazards, the USGS
Western Geographic Science
Center is developing new ways to
assess and communicate societal
risk and resilience to catastrophic
and chronic natural hazards.

The United States faces multiple natural hazards that threaten its safety, security, economic wellbeing, and natural resources. To balance near-term economic interests with long-term sustainability goals, as well as prepare for and recover from disasters, public officials, emergency and other managers, businesses, and at-risk individuals need a clear understanding of both societal risk from various threats and strategies to increase resilience.

Societal risk and resilience to natural hazards are complex phenomena, involving the exposure, sensitivity, and adaptive

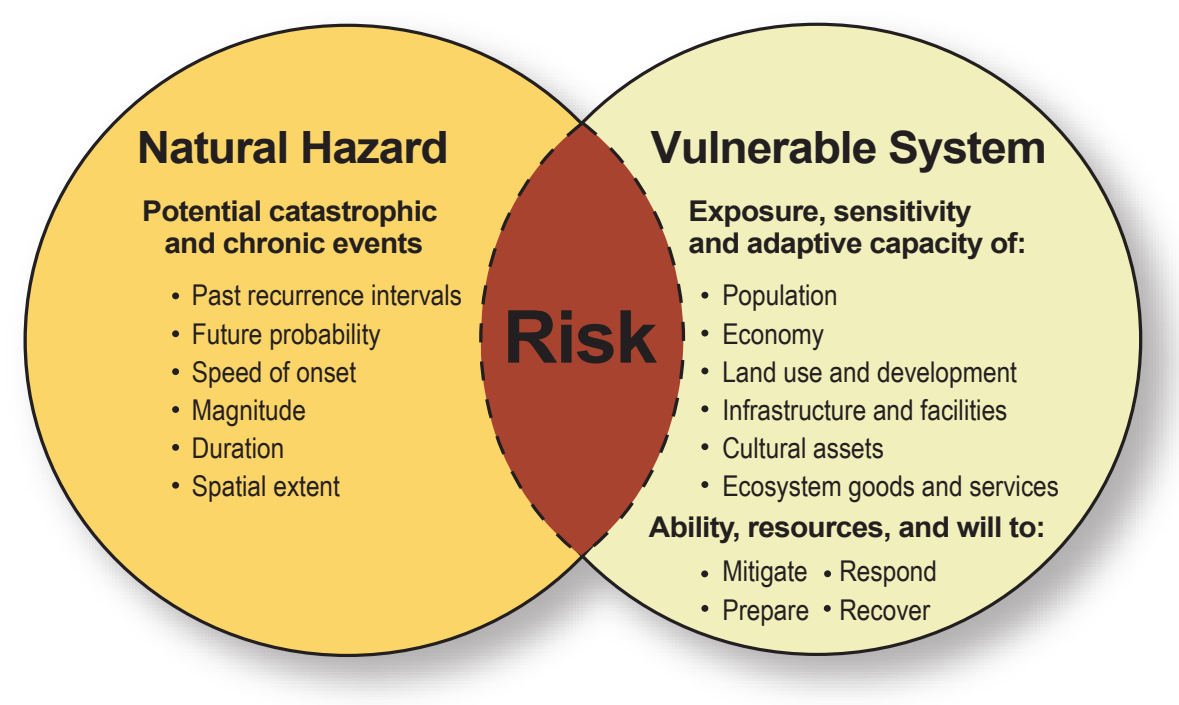

Risk is not only a function of exposure to natural processes that can impact society but also a function of the choices we make as we inhabit a dynamic Earth. Impacts of events directly relate to human decisions and policies made before, during, and after a catastrophic event.

capacity of human-environmental systems. These aspects of vulnerability are a function of (1) existing patterns of land use and land cover, (2) current socioeconomic conditions, (3) likely patterns of future land use, and (4) current efforts to mitigate, adapt to, or prepare for future events or conditions.

The U.S. Geological Survey (USGS) Western Geographic Science Center (WGSC) and the USGS Geographic Analysis and Monitoring (GAM) Program are

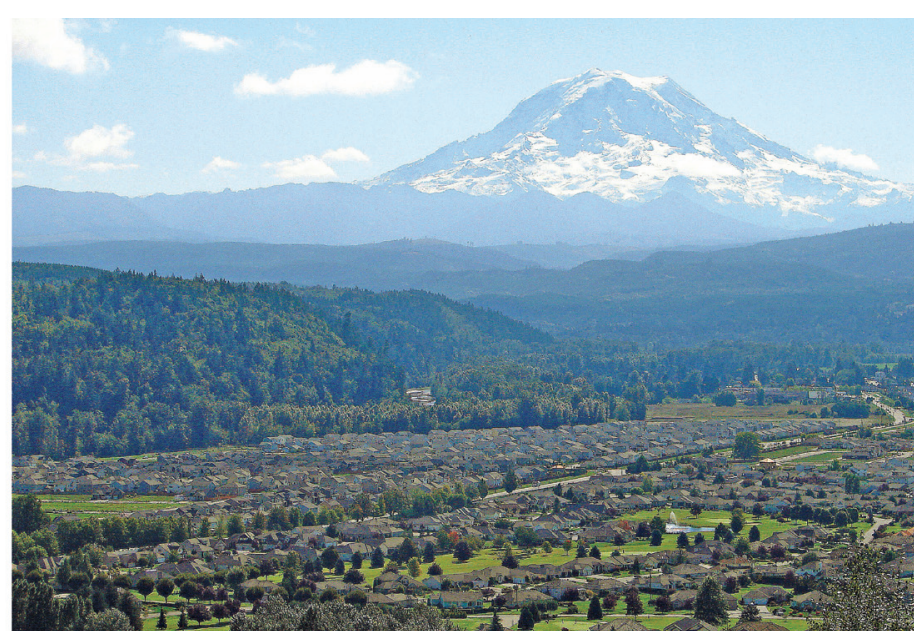

How communities use hazard-prone land influences their vulnerability to future extreme events, such as volcanic mudflow (lahar) hazards associated with volcanoes. This photograph shows an area at risk from lahars from Mount Rainer, Washington. (USGS photo by Nathan Wood.) committed to improving the Nation's understanding of where and how it is vulnerable to natural hazards, what options exist for reducing unacceptable risks, and how to effectively respond so that recovery is rapid when catastrophes occur. Communities can use this information to reduce the impacts on quality of life and resources from future disasters.

\section{Benefits of Understanding Risk}

- Focuses public attention on controllable societal consequences of events instead of on uncontrollable natural processes;

- Identifies regions or areas that may warrant new risk-adaptation strategies, preparedness plans, public education, or land-use changes;

- Serves as baseline information for response efforts; and

- Highlights where additional hazard, risk, or mitigation assessments may be needed or improved. 


\section{WGSC Approaches to Understanding and Communicating Risk to Natural Hazards}

\section{Exposure Assessments}

Variations in community exposure and potential losses from hazards are summarized in terms of land cover, populations, economic assets, and critical infrastructure. This image shows various types of land cover in a tsunami-hazard zone

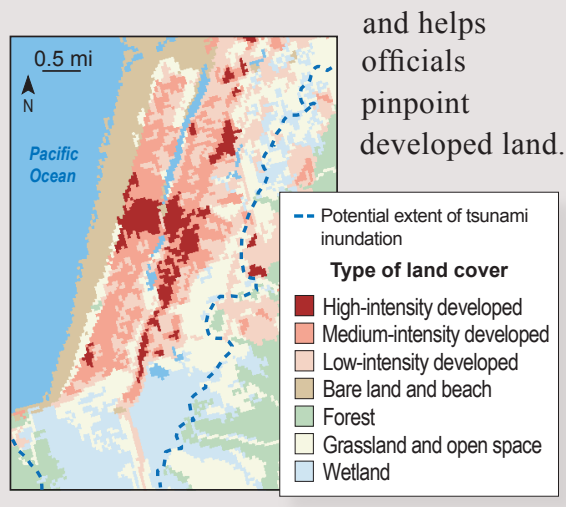

\section{Recent WGSC Contributions to Understanding Risk and Resilience to Natural Hazards}

\section{Washington}

Working with the State of Washington Emergency Management Division, WGSC scientists have assessed variations in community exposure on the open-ocean coast to tsunami hazards related to a Cascadia subduction zone earthquake (http://pubs.usgs.gov/ sir/2008/5004/). Evacuation modeling is being done to examine the ability of at-risk individuals to reach higher ground before tsunami inundation. Variations in exposure to volcanic mudslide (lahar) hazards have been assessed for communities downstream of Mount Rainier (http://pubs.usgs.gov/sir/2009/5211/). WGSC scientists are working with the USGS Volcano Hazards Program and USGS Earthquake Hazards Program to examine community exposure to 4 other active volcanoes and 20 earthquake scenarios.

\section{Oregon}

WGSC has assessed variations in community exposure along the Oregon coast to tsunami hazards associated with a Cascadia subduction zone earthquake (http://pubs. usgs.gov/sir/2007/5283). Hotspots of demographic sensitivity to Cascadia tsunamis were mapped in collaboration with the University of South Carolina, and land-cover data derived from Landsat Thematic Mapper satellite imagery were shown to be an effective tool in assessing community ex-

\section{Geospatial and Economic Modeling}

Modeling efforts that leverage geospatial data have addressed pedestrian evacuations, demographic sensitivity, economicloss estimation, and the evaluation of alternative mitigation strategies. This image shows hotspots of relative demographic

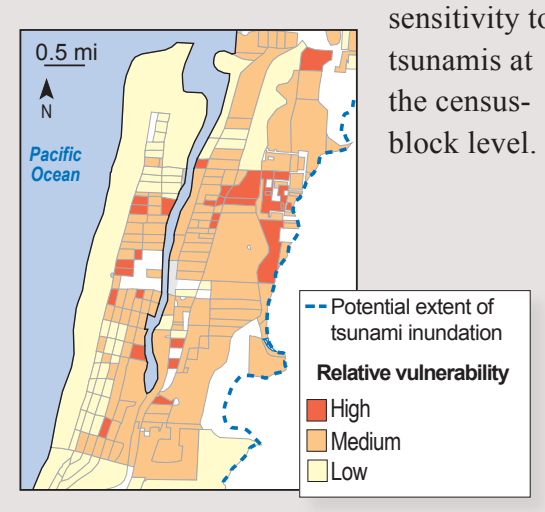

posure to tsunamis. Community workshops have been held to discuss vulnerability and post-disaster recovery from tsunamis. In cooperation with Clackamas County, WGSC scientists are examining population exposure and adaptive capacity to hazards associated with Mount Hood volcano. Working with Oregon State University and State agencies, WGSC is also examining vulnerability to coastal-erosion hazards enhanced by changing climatic conditions.

\section{California}

As part of the USGS Multi-Hazard Demonstration Project, WGSC has led efforts to characterize the social and economic consequences of a magnitude 7.8 earthquake scenario in southern California (http:// pubs.usgs.gov/of/2008/1150/), an extreme winter-storm scenario for California (http:// pubs.usgs.gov/of/2010/1312), and a tsunami scenario affecting southern California ports. Expertise in decision analysis is being applied to wildfire risk. These efforts include broad cooperation across governmental agencies and workshops with scientists, emergency managers, and community leaders and other stakeholders to develop estimates for infrastructure damages, agricultural damages, lifeline service restoration, and business interruption losses.

\section{Hawai‘i}

WGSC scientists, working through the Pacific Risk Management 'Ohana (PRiMO) initiative, in cooperation with researchers
Stakeholder Engagement

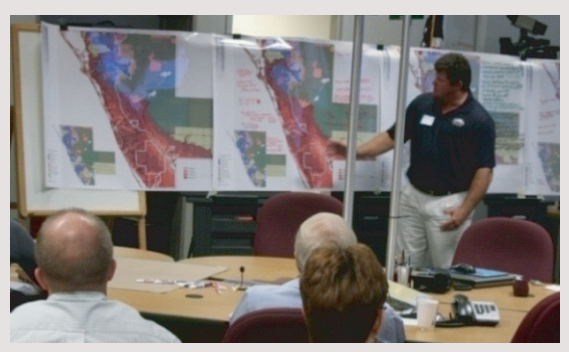

Risk is subjective and influenced by the perceptions and willingness to adapt of those at risk. The WGSC works with officials and the public to understand the societal context of risk and to effectively communicate results. This photograph shows a stakeholder pointing out vulnerability issues on a map of hurricane storm-surge zones enhanced by sea-level rise scenarios. (USGS photo by Nathan Wood.)

at The Pennsylvania State University and State of Hawai'i representatives, assessed variations in community exposure to tsunamis across Hawai 'i (http://pubs.usgs. gov/sir/2007/5208/). A similar analysis was done to examine current societal exposure to storm-surge inundation zones observed during Hurricane Iniki in 1992 (http://pubs. usgs.gov/of/2008/1280/).

\section{Florida}

In collaboration with The Pennsylvania State University, WGSC examined societal vulnerability in Sarasota County, Florida, to hurricane storm-surge hazards that included sea-level rise scenarios. Research included an analysis of variations in community exposure to hazards and a workshop to document stakeholder perspectives on land-use strategies to adapt to hazards.

\section{Nathan Wood}

Edited by James W. Hendley II Graphics and layout by Judy Weathers

For more information, contact:
Nathan Wood
U.S. Geological Survey
1300 SE Cardinal Court, Bldg. 10, Suite 100
Vancouver, WA 98683
Tel. (360) 993-8951
nwood@usgs.gov
http://geography.wr.usgs.gov/
http://geography.wr.usgs.gov/science/
vulnerability/
This Fact Sheet and any updates to it are available online
at
http://pubs.usgs.gov/fs/2011/3008/

